\title{
Influence of rheology on debris-flow simulation
}

\author{
M. Arattano ${ }^{1}$, L. Franzi ${ }^{2}$, and L. Marchi ${ }^{3}$ \\ ${ }^{1}$ CNR-IRPI, Strada delle Cacce,73, 10135 Torino, Italy \\ ${ }^{2}$ Regione Piemonte, Corso Tortona, 12, 10183 Torino, Italy \\ ${ }^{3}$ CNR-IRPI, C.so Stati Uniti, 4, 35127 Padova, Italy
}

Received: 1 August 2005 - Revised: 21 February 2005 - Accepted: 6 March 2006 - Published: 12 June 2006

Part of Special Issue "Documentation and monitoring of landslides and debris flows for mathematical modelling and design of mitigation measures"

\begin{abstract}
Systems of partial differential equations that include the momentum and the mass conservation equations are commonly used for the simulation of debris flow initiation, propagation and deposition both in field and in laboratory research. The numerical solution of the partial differential equations can be very complicated and consequently many approximations that neglect some of their terms have been proposed in literature. Many numerical methods have been also developed to solve the equations. However we show in this paper that the choice of a reliable rheological model can be more important than the choice of the best approximation or the best numerical method to employ. A simulation of a debris flow event that occurred in 2004 in an experimental basin on the Italian Alps has been carried out to investigate this issue. The simulated results have been compared with the hydrographs recorded during the event. The rheological parameters that have been obtained through the calibration of the mathematical model have been also compared with the rheological parameters obtained through the calibration of previous events, occurred in the same basin. The simulation results show that the influence of the inertial terms of the Saint-Venant equation is much more negligible than the influence of the rheological parameters and the geometry. A methodology to quantify this influence has been proposed.
\end{abstract}

\section{Introduction}

Land-use planning and design of structural countermeasures for debris flows are generally carried out on the basis of the analysis of past events or using the results obtained by the application of mathematical models. The first approach can give useful indication on the possible effects of future debris flow events, but it cannot give more detailed predictions of their effects (Suwa and Yamakoshi, 2000; Ayotte and Hungr, 2000). The application of mathematical models is employed to obtain more quantitative estimations of the dynamic characteristics of debris flows (velocity, flow depth, discharge, flow duration, etc.). The estimation of the dynamic characteristics of debris flows is in fact needed by administrators, decision makers and practitioners who have to protect the life, the property and the economical activities of people who live in debris flows prone areas and to forbid anthropic activities in these latter (Regione Piemonte, 2002; Petrascheck and Kienholz, 2003). Sometimes different boundary conditions (e.g. water-sediment hydrograph, peak discharge) are taken into account in order to test the sensitivity of the results and the adequacy of the designed/existing countermeasures. When a more detailed hazard assessment is needed, especially for relocation of settlements and human activities, more complex mathematical models can be used (2-D models, two phase models, movable bed models that can incorporate depositions and erosions along the torrent) (Ghilardi and Natale, 2000; Pudasaini et al., 2003, 2005). However the estimation of the parameters to be used in the simulations is often not straightforward and the choice of the more apt rheological model can be very difficult. In this paper the simulation of a debris flow event occurred in 2004 in an instrumented torrent will be presented and the influence on results of the rheological parameters will be discussed. A one-phase Saint-Venant model has been used for the simulation because the available field data allowed to calibrate only 2 parameters: the calibration of 2-D models would have required more parameters. At the moment, in the field practice, 1-D models are still more commonly employed than 2-D models. This paper should offer an help to practitioners to better understand the performances of 1-D models.

Correspondence to: M. Arattano

(m.arattano@irpi.cnr.it)

Published by Copernicus GmbH on behalf of the European Geosciences Union. 

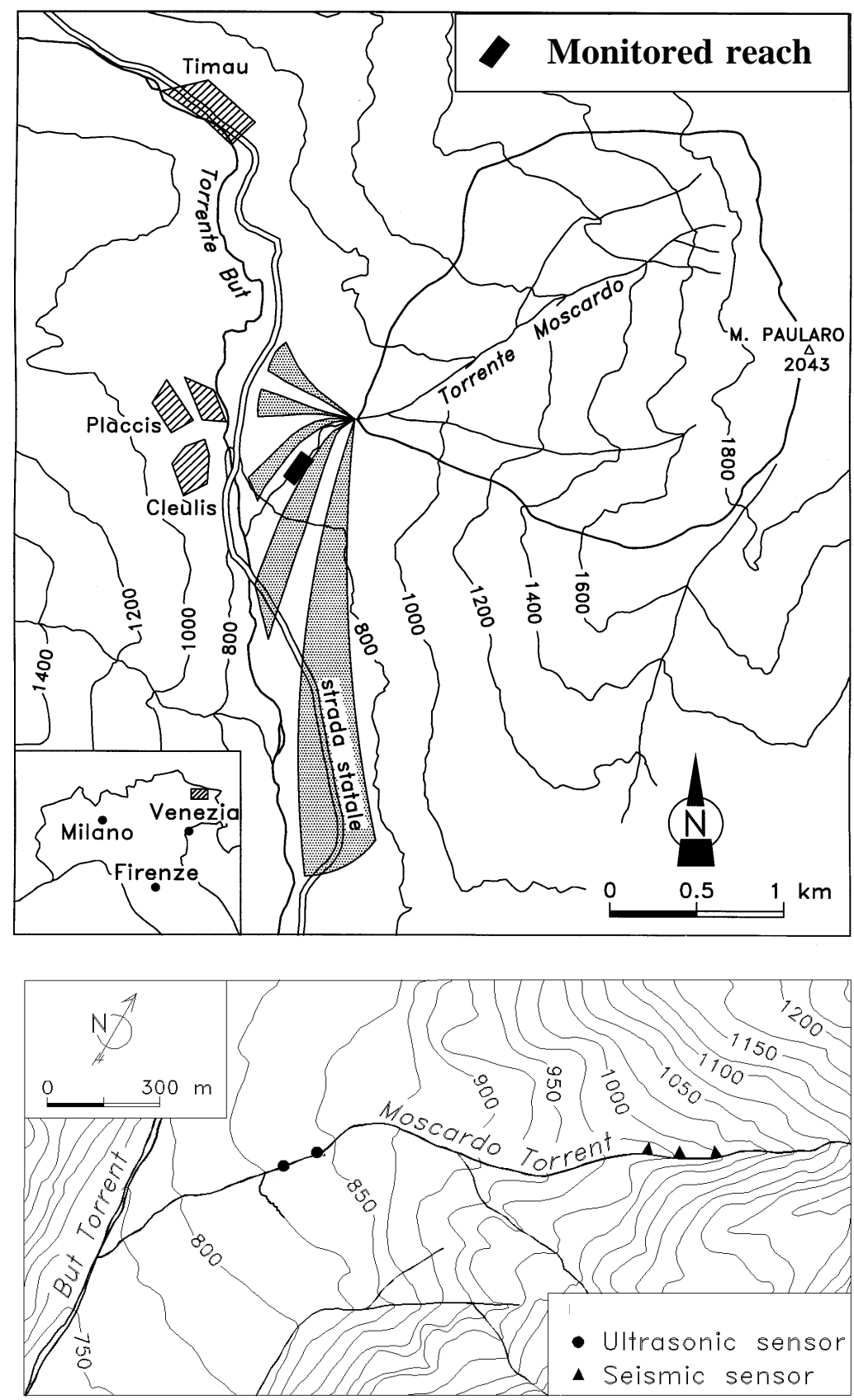

Fig. 1. The Moscardo basin and its geographical location.

\section{The simulated debris flow event}

The Moscardo torrent is a small torrent, located in the Eastern Italian Alps, that has been affected in the past by several debris flows (Marchi et al., 2002). It drains an overall area of about $4 \mathrm{~km}^{2}$ ranging in elevation from $890 \mathrm{~m}$ to $2043 \mathrm{~m}$ above the sea level (Fig. 1).

In 1989 two ultrasonic sensors were placed on the fan of the torrent where the bed slope is approximately $10 \%$ and the torrent reach is quite straight. These sensors measured the stage performing three measurements each second with a precision of about $1 \mathrm{~cm}$ and allowed the recording of an hydrograph that show the stage variation in time. In 1996 a third sensor was added upstream of the previously installed sensors and was maintained active until 1998. Nowadays only two ultrasonic sensors are installed along the torrent, $75 \mathrm{~m}$ apart. The cross section width of the torrent reach is about $8 \mathrm{~m}$. This cross section can be modelled as a broad rectangular section. 
A debris flow event occurred on 23 July 2004 that was characterised by a first water-sediment surge that lasted about $400 \mathrm{~s}$, followed by a second surge which lasted about $100 \mathrm{~s}$. The first wave had a steeper front and greater flow depths that decreased after the peak. The second wave was shorter, with a lower gradient in the front part. A superposition of the upstream and downstream hydrographs reveals that no evident modification of the shape of the debris flow wave occurred between the two stations. The event duration is also the same in the two hydrographs. Since the geometry of the channel does not change along the torrent reach between the ultrasonic gauges, the absence of a significant hydrograph deformation suggests that no significant deposition/erosion processes occurred between the two sites.

\section{The mathematical model}

The mathematical model employed is the same 1-D model already proposed and discussed in Arattano and Franzi (2003, 2004). A 2-D model would have actually allowed to consider, for instance, the boundary effects due to the side of the channel; however, as mentioned before, the available field data would have not allowed to calibrate it.

Applying the momentum and mass conservation laws to the mixture of a debris flow, a system of two partial differential equations is obtained, namely the Momentum equation and the Mass conservation equation (Cunge et al., 1980; Abbott, 1966), that can be solved with an implicit finitedifference scheme, according to Preismann (Cunge et al., 1980; Abbott, 1966):

$$
\left\{\begin{array}{l}
\frac{\partial Q}{\partial t}+g A \frac{\partial h}{\partial x} \cos \theta+\frac{\partial}{\partial x}\left(\frac{Q^{2}}{A}\right)+g A S_{f}-g A \tan \theta=0, \\
\frac{\partial h}{\partial t}+\frac{1}{b} \frac{\partial Q}{\partial x}=0
\end{array}\right.
$$

where $Q$ is the water-sediment discharge, $A$ is the cross section area occupied by the debris flow, $b$ is the free debris flow surface width in the cross section, $h$ is the flow depth, $\theta$ is the bed slope angle (assumed constant), $S_{f}$ is the friction term that accounts for internal and external friction, $x$ is the downstream coordinate (positive downstream), $g$ is the gravity acceleration. The effects of the centrifugal forces (Pudasaini and Hutter, 2003) are not taken into account because the investigated reach of the Moscardo Torrent is straight.

The first term on the left side of the first equation of the system (1) represents the effects of the local inertia, the second term the pressure effects, the third the convective inertia, the fourth the effects of internal and external friction and the fifth the gravity effects. According to the different topographic and dynamic conditions, different terms can play different roles in the simulation. In particular the inertia terms can be considered to be predominant in time and space varying processes, such as floods due to dam breaks. The fourth term can be expressed in different ways, according to the different rheological behaviors of the water-sediment current.
A detailed discussion of this latter issue can be found in Arattano and Franzi (2003). The rheological properties of the water sediment mixture must be specified to solve the system (1). The following closure equation has been used, following Honda and Egashira (1997):

$\tau=\tau_{o}+\rho g h \frac{U^{2}}{c^{2} h^{2 n}}$,

where $\tau_{o}$ is the yield stress, $c$ and $n$ are two rheological parameters, $\rho$ is the fluid density and $U$ is the mean flow velocity in the cross section. Equation (2) is one of the most generic equation for debris flows simulation as it takes into account the presence of a yield strength and a stress. The term $S_{f}$ in (1) is linked to $\tau$ through the following relationship:

$S_{f}=\frac{\tau}{\rho g h}$

The debris flows of the Moscardo Torrent have a heterogeneous grain size: transported particles range from silt and clay to boulders (Arattano et al., 1997). On the basis of the video recorded images of some events (Deganutti et al., 1998) we have assumed that the coarse fraction gives to the overall mixture a rather high drainage capability, although no experimental measurements are available on this aspect. We thus deem that the effect due to the excess-pore fluid pressure (Hungr, 1995; Hutter et al., 1996; Iverson, 1997) can be neglected. This hypothesis is equivalent to state that the excess pore pressure, if present, dissipates in time-scales much smaller than the time scale of the water-sediment propagation. Actually, as far as the debris flow front is concerned, this latter sustains generally little pore pressure and exerts much frictional resistance because it is composed by a wedge of coarse particles with a high hydraulic diffusivity. The issue about the role of pore pressure would therefore concern only the debris flow body; in the tail in fact non-hydrostatic pore-pressure dissipates more rapidly than in the body (Iverson et al., 2000). The large dimensions of coarse particles in the 2004 debris flow and the little amount of clay in the mixture suggests the existence of a very high hydraulic diffusivity also in the debris flow body and thus a ready dissipation of the non-hydrostatic pore pressures. In these conditions the total stress on the bed would be equal to the hydrostatic stresses plus the static/dispersive stresses due to contacts/collisions among particles. In these conditions the term $\left(\partial \mathrm{p}_{b e d} / \partial \mathrm{x}\right)$ (Iverson, 1997, 2000; Jin and Fread, 1999) tends to be equal to zero and the pore pressure distribution tends to be hydrostatic. A hydrostatic distribution of the pore pressure is a basic assumption of many rheological models (Takahashi, 1991; Egashira et al., 1997) that imply resistance to flow formulas similar to Eq. (2).

Different values have been proposed for the rheological parameters $c$ and $n$ by different authors, as sumarized in Table 1. 
Table 1. Some proposed values for the rheological parameters $c$ and $n$. The $c$ dimensions depend on the value of $n$.

\begin{tabular}{|c|c|c|}
\hline \multirow[t]{2}{*}{ Author } & \multicolumn{2}{|c|}{ Simulation parameters } \\
\hline & $\begin{array}{c}n \\
{[-]}\end{array}$ & {$\left[\begin{array}{c}c \\
{\left[\mathrm{~m}^{1-n} / \mathrm{s}\right]}\end{array}\right.$} \\
\hline $\begin{array}{l}\text { Rickenmann } \\
\text { (1999) }\end{array}$ & $1 / 3,1 / 2$ & $\begin{array}{l}c \text { depends on the parameter } n \text { and on } \\
\text { the debris flow peak discharge }\end{array}$ \\
\hline $\begin{array}{c}\text { Takahashi } \\
\text { (1991) } \\
\text { Takahashi and Nakagawa } \\
\text { (1993) }\end{array}$ & $\begin{array}{l}3 / 2 \\
\text { (theoretical and laboratory } \\
\text { results) }\end{array}$ & $\begin{array}{l}\text { For dilatant flow behaviour } c \text { depends on } \\
\text { the sediment concentration } C \text {, by volume, } \\
\text { the interstitial fluid density and the mean grain size }\end{array}$ \\
\hline $\begin{array}{l}\text { Coussot } \\
(1994)\end{array}$ & $\begin{array}{c}3 \\
\text { (Herschel-Bulkley model) }\end{array}$ & muddy debris flows and mudflows \\
\hline
\end{tabular}

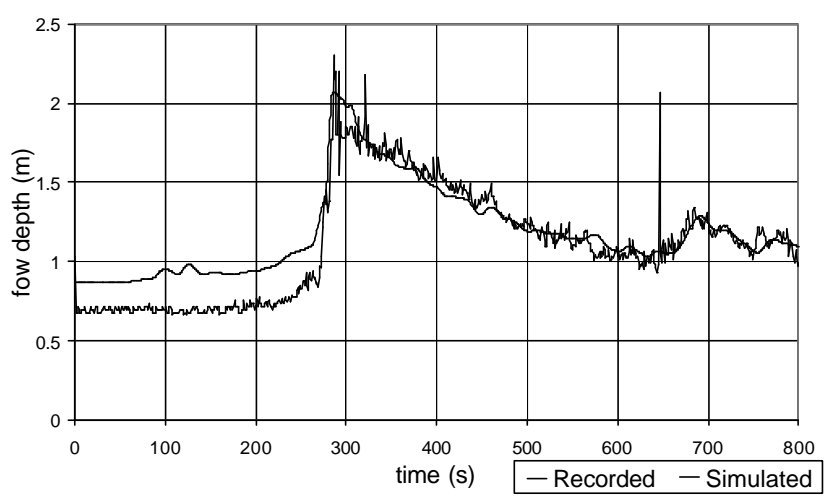

Fig. 2. Water sediment flow depths in the upstream cross section.

The value of the parameter $n$ depends on the rheological behavior of the debris flow mixture, as summarized by Pierson and Costa (1987). The term $\tau_{o}$ in (2) is responsible for the presence of a rigid plug in the flowing mixture and a critical thickness for the flow, below which motion should stop and the debris flow should deposit. Previous researches in the Moscardo torrent have shown that a rigid plug flow is not always observed for the debris flows in this torrent (Deganutti et al., 1998) while many of the hydrographs recorded so far show a descending limb that does not show any critical thickness below which a stop of the motion is observed (Marchi et al., 2002; Arattano and Franzi, 2004). Therefore (2) was implemented in the simulation with $\tau_{o}=0$ (Nsom et al., 1998). The resulting equation is often used in practical applications (Rickenmann, 1999). It probably works better when the torrent is incised and the banks allow the maintenance of a high water content, particularly behind the front and in the tail of the debris flow: a high water content maintain the mixture less dense and more fluid reducing the effects or even eliminating the presence of a yield stress. Note that Eq. (2) with $\tau_{o}=0$ approximates the Herschel-Bulkley or the Bingham model for small yield stress.

In the simulation the values of $c$ and $n$ have been adopted that allowed best fit to the upstream hydrograph. A steady flow has been assumed for the initial conditions along the entire torrent reach in order to solve the system of Eqs. (1). The assumed upstream boundary conditions for $h$ are given by the upstream recorded hydrograph (Fig. 2). Therefore the initial and boundary conditions are, respectively, the following:

$\left\{\begin{array}{l}t=0 \\ U=U(x, 0) ; h=h(x, 0) \text { for } 0<x<L \text { steady flow }\end{array}\right.$

$\left\{\begin{array}{l}x=0 \\ \left.U=f[h(0, t)]=c h^{n} \sqrt{S}_{f} ; h=h(0, t) \text { for }\right)<t<800 \mathrm{~s}\end{array}\right.$

where:

- $L$ is the length of the torrent reach, equal to the distance between the first and the second gauging station $(75 \mathrm{~m})$,

- $U=U(x, 0)$ and $h=h(x, 0)$ have been obtained by solving system (1) where all the time derivative terms have been set equal to zero (steady flow conditions);

- $h(0, t)$ is the hydrogram in the upstream cross section.

As indicated before, the $U(0, t)=f[h(0, t)]$ relationship in the upstream reach depends on the choice of the simulation parameters. Since the $h(0, t)$ values in Eq. (5) are those recorded in the upstream hydrograph, the uncertainty in the estimation of $U$ and consequently in the estimation of the debris flow discharge is much smaller than in other simulations where both the upstream conditions, $h$ and $U$, had to be estimated (Honda and Egashira, 1997; Hirano et al., 1997). The assumption of uniform flow conditions in the upstream boundary can be found in other models (e.g. Hirano et al., 


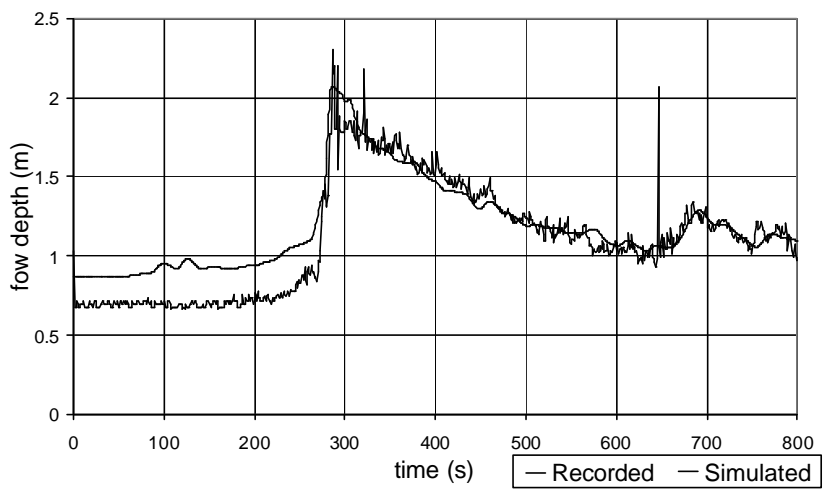

Fig. 3. Comparison between the recorded and simulate hydrograph in the downstream cross section $(70 \mathrm{~m}$ downstream). Notice that the different flow depths for $\mathrm{t}<270 \mathrm{~s}$ occur because the rheological parameters have been used also in the simulation for $\mathrm{t}<270 \mathrm{~s}$ when the flow consisted mostly of clear water.

1997; Suzuky et al., 1993; Arattano and Savage, 1994). For steep bed slopes the assumption of uniform flow conditions can be the most reasonable, because there is a predominance of the gravity and friction terms in Eq. (1) (Cunge, et al., 1980). For the examined debris flow the assumed initial and boundary conditions are reliable and reasonable and they certainly do not produce a strong influence on the results. In fact, as the discussion that follow will put into light, the unsteady terms in system (1) are far less than the other terms.

Different simulations have been performed for different $c$ and $n$ values maintaining the same boundary and initial conditions. The best fit between the recorded and the simulated hydrographs was obtained for $c=4 \mathrm{~m}^{0.8} / \mathrm{s}$ and $n=1.2$. The comparison between the recorded downstream hydrograph $h^{\prime}, t$ and the simulated hydrograph $h^{\prime \prime}, t$ is quite satisfactory (Fig. 3). Notice that the higher flow depth in the simulated results of Fig. 3, before the surge reaches the gauge, is due to the fact that we have applied the rheological parameters found in the simulation to the entire wave as if it were made of the same mixture. Actually the flow preceding the surge was entirely different and consisted mostly of clear water.

The recorded hydrograph (Fig. 3) shows oscillations due to the irregularities of the debris flow profile. These are due to the pebbles, cobbles, stones, trees and smaller pieces of vegetation that are transported on the surface of the debris flow itself and to splashes and other turbulences, including small waves, that take place on the debris flow surface. The relative error in the measured hydrograph is also due to the error of the instrumental recording device and to the value of the time interval of the measurement (one second).

The recorded hydrographs allow to compute the total volume of debris flowing through the two cross sections, as described in Arattano (2000). The coincidence of the curves representing the total volumes of debris flows at the two gauging stations (Fig. 4) seems in agreement with one of

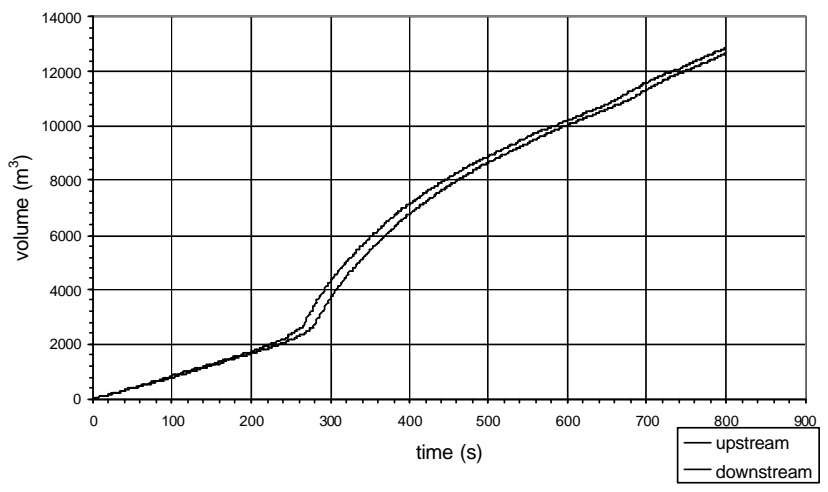

Fig. 4. Comparison between estimated volumes upstream and downstream.

the basic assumption of the model: the absence of deposition/erosion processes along the monitored torrent reach.

\section{Debris flow rheology}

The simulation results have been obtained for an unsteady one-dimensional model with initial and boundary conditions deduced from recordings or from empirical evaluations. If a reliable estimation of the initial and boundary conditions is possible, the higher uncertainties in the simulation results are either due to the uncertainties in the assumption of the rheological behavior or to other aspects of the modeling of the debris flow. In the following this point will be discussed in a greater detail. It will also be shown that, for the studied case, a simple model that neglects the inertial terms of the Saint-Venant equation can give good simulation results.

\subsection{Rheological behaviour of the debris flow - discussion}

The rheological properties of a debris flow affect its dynamic characteristics and, therefore, the amount of the dynamic impact against defence structures. The impact forces exerted on levees or dams are generally obtained and quantified through the application of the momentum transfer principle or through the energy conservation theorem. The prediction of the rheological behaviour usually relies on observations of past events occurred in the same area. The field data collected in the Moscardo Torrent, since the inception of the monitoring activities, have provided important information regarding this latter issue. Following the same procedure employed in this paper the debris flows that occurred on 20 July 1993, 22 June 1996, 8 July 1996 and 4 August 2002 have been previously modelled (Arattano and Franzi, 2003, 2004). Table 2 summarises the values of $c$ and $n$ found for these events.

As far as the July 2004 event is concerned, the values found for the parameters of the model are similar to the parameters found for the event occurred on 4 August 2002. The 
Table 2. Comparison of the simulation parameters for the 1993, 1996, 2002 and 2004 Moscardo events.

\begin{tabular}{cccccc}
\hline & 20.07 .1993 & 22.06 .1996 & 08.07 .1996 & 04.08 .2002 & 23.07 .2004 \\
\hline$c(*)$ & 14 & 14 & 14 & 5 & 4 \\
\hline$n(-)$ & 0.2 & 0.2 & 0.66 & 1.3 & 1.2 \\
\hline
\end{tabular}

$(*)$ unit of $c$ depend on $n$ value, according to the relationship $[c]=\mathrm{m}^{(1-n)} / \mathrm{s}$.

deposits of this latter event, surveyed few days after its occurrence (Arattano and Franzi, 2004), appeared to be quite coarse and with a very small fine fraction. These field evidences led to interpret this debris flow as a stony debris flow. Therefore the value of $n$ that resulted from the simulation of the 4 August 2002 event was considered as indicative of a flow behaviour of the dilatant type, as that proposed by Takahashi $(1978,1980,1991)$ (Arattano and Franzi, 2004). The same behaviour can be hypothesized for the July 2004 event.

The large variation of the $c$ and $n$ values shown in Table 2 suggests that the rheological coefficients are not constant, even for debris flows taking place in the same torrent. This implies that, for purposes of hazard prediction and assessment on a debris fan, different simulations have to be performed assuming different rheological behaviors and exploring the related consequences. Both $c$ and $n$ have a strong influence on the dynamics: therefore, for practical applications of the proposed methodology, a sensitivity analysis of the results for different $[n, c]$ pairs should also be performed. In SEct. 4.3 this point will be further discussed.

4.2 Influence on simulation results of the terms of the Saint-Venant equation

A numerical scheme is needed to solve the partial differential equations (1) for given initial and boundary conditions. Many schemes have been proposed in literature (Jan, 1997; Hashimoto et al., 2000; Cunge at al., 1980), either implicit or explicit, either one step or multisteps. In general the greatest difficulties in the numerical solutions are represented by the non linear terms (e.g the convective term) and by the necessity to simulate dam-break like hydrographs with rapidly varying flow depths, discharges and velocities. Different numerical methods have been proposed to obtain stable mathematical algorithms and consistent schemes (Cunge at al., 1980; Abbott, 1992). In general, some simplifications of system (1) may apply if the boundary and geometrical conditions allow to neglect some of the terms in the momentum equation. However it is often not easy to choose which term can be neglected, because the influence of the differential terms cannot be evaluated "a priori", given their strong variation in time and space during the simulation.

Here a comparison has been carried out of the values and the related influence of the different terms in system (1). As stated before, for steep bed slopes, the influence of the fourth and fifth term in the momentum equation can be predominant on the other terms so that the propagation model can be strongly simplified. The resulting model is the so-called "kinematic model" (Arattano and Savage, 1994). The momentum equation holds in this case:

$S_{f}=\tan \theta$

Computing the difference between the bed slope, $\tan \theta$, and $S_{f}$, that is the computed value of the energy gradient, it is possible to obtain an estimation of the error due to the approximation introduced in the computation with the neglecting of the differential terms in system (1) and thus evaluate their influence:

$-\frac{1}{g A}\left[\frac{\partial Q}{\partial t}+g A \frac{\partial h}{\partial x} \cos \theta+\frac{\partial}{\partial x}\left(\frac{Q^{2}}{A}\right)\right]=S_{f}-\tan \theta$

The relative error, $\varepsilon_{k}$, due to the neglecting of the differential terms in system (1) will be given by:

$\varepsilon_{k}=\frac{S_{f}-\tan \theta}{\tan \theta}$

The relative error, $\varepsilon_{k}$, is linked to the relative error in the estimation of the flow height $h$. In fact rewriting Eq. (2), with $\tau_{o}=0$ holds:

$h=\sqrt[2 n]{\frac{U^{2}}{S_{f} c^{2}}}$

Recalling that the term $S_{f}$ is given by:

$S_{f}=\frac{\tau}{\rho g h}$

and differentiating Eq. (9) with respect to $S_{f}$ for a constant discharge, the following equation can be obtained (see appendix):

$\frac{\partial h}{h}=-\frac{1}{2(n+1)} \frac{\partial S_{f}}{S_{f}}$.

The term $\partial \mathrm{S}_{f} / S_{f}$ can be assumed as an estimation of the relative error in the evaluation of $S_{f}$. Equation (6) states that $S_{f}$ can be approximately assumed equal to $\tan \theta$, thus the error $\partial S_{f}$ will be given by $S_{f}-\tan \theta$ and the relative error $\partial$ $S_{f} / S_{f}$ will be given by:

$\frac{\partial S_{f}}{S_{f}}=\frac{S_{f}-\tan \theta}{S_{f}}$. 


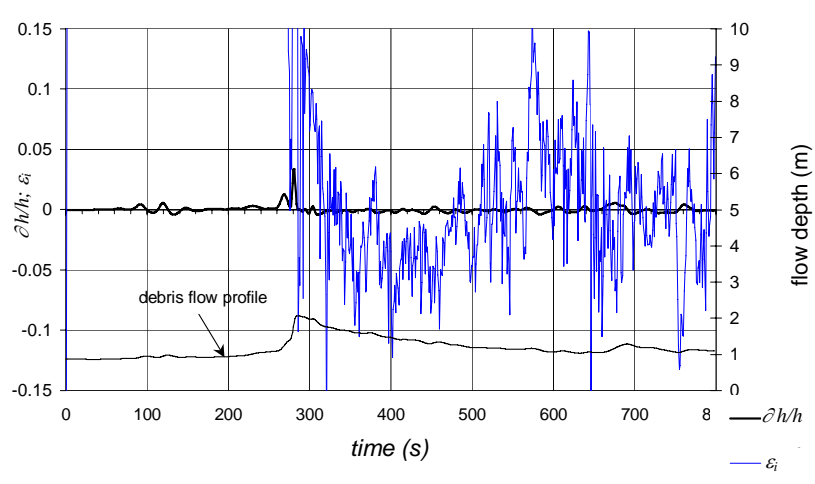

Fig. 5. Variation of $\partial h / h$ in Eq. (10) and $\varepsilon_{i}$ in time. The relative error $\varepsilon_{i}$ has been plotted only for $\mathrm{t}>270 \mathrm{~s}$ (see Fig. 2). The simulated debris flow profile has been shown.

Considering that, for steep bed slopes, $S_{f}$ is actually very close to $\tan \theta$, the denominator of Eq. (11) can be substituted by $\tan \theta$, and thus $\partial S_{f} / S_{f}$ is approximately equal to $\varepsilon_{k}$ (Eq. 8). Equations (8), (10) and (11) thus shows then that the relative error, $\varepsilon_{k}$, due to the neglecting of the differential terms in system (1) is directly related to the relative error, $\partial$ $h / h$, in the evaluation of $h$. The relative error $\varepsilon_{k}$ can thus be assumed as an indicator of the relative error in the estimation of $h$ made with the kinematic simplification given by Eq. (6).

Since the value of the right-hand-side term in Eq. (11) and consequently the value of $\partial S_{f} / S_{f}$, can be calculated by means of the results of the simulation, the relative error $\varepsilon_{k}$ made in our simulation can be obtained from Eq. (10) (substituting the value of $\partial S_{f} / S_{f}$ obtained through the simulation and assuming $n=1.2$ ). We calculated the value of $\varepsilon_{k}$ following this procedure and we found that, for the larger debris flow wave of the July 2004 event, $\varepsilon_{k}$ was generally less than $1 \%$. It resulted higher than $1 \%$ only twice, for 6 and $5 \mathrm{~s}$, respectively. In the latter time interval, $\varepsilon_{k}$ reached a maximum value of $2.96 \%$. This shows that the approximated assumption made in Eq. (6) affects the results, as far as the estimation of flow depth is concerned, only by some percentages. This influence appears even more negligible if the irregularities in the debris flow profile that are due to the presence of pebbles, cobbles, wood debris and superficial waves are taken into account. These irregularities impede a good match between the simulated hydrograph $\left\{h^{\prime}, t\right\}$ and the recorded one $\left\{h^{\prime \prime}, t\right\}$. Actually the relative error made in the estimation of $h$, given by Eq. (8), is much smaller than the relative error $\varepsilon_{i}$ produced by the inadequacy of the model to reproduce the irregularities of the real debris flow profile:

$\varepsilon_{i}=\frac{h^{\prime}-h^{\prime \prime}}{h^{\prime \prime}}$

as shown in Fig. 5. Notice that the large value of $\varepsilon_{i}$ is predominantly due to the complexity of the examined phenomenon with its irregular profile. This irregularity of profile

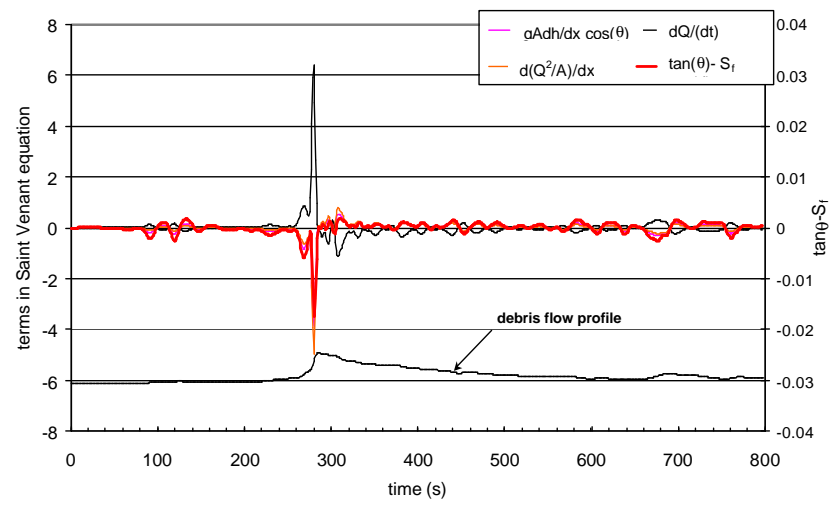

Fig. 6. Variation in time of the different terms in Saint Vent Equation, in the downstream cross section. The recorded debris flow profile has been solely indicated to provide an indication about the points where the term were calculated along the wave profile.

can not be predicted with deterministic mathematical tools. For our examined event, even if a more complex model were used, with a complete Saint Venant equation, no significant improvement in the results would be obtained. This can be also shown, from a mathematical point of view, by computing the magnitude of the differential terms in the momentum equation. Figure 6 shows that the value of the differential terms of Eq. (7), given by $\tan \theta-S_{f}$, is very small [ranging between -0.0174 and +0.00179 ] along the entire wave: including them in the equation would have not changed the results. The results shown in Fig. 6 refer to the downstream cross section.

Figure 6 also shows that the influence of all the non-linear terms on the left hand of Eq. (7) is far less than the bed slope itself. According to the obtained results, the left hand term in Eq. (7) is higher (in module) than 0.01 for only $3 \mathrm{~s}$. Moreover the differential terms on the left hand of Eq. (7) have an opposite sign thus eliding each other. All this supports the applicability of the kinematic model to the examined case.

\subsection{Influence of rheology on simulation results}

According to Eq. (9), the evaluation of the water-sediment depth $h$ depends on the estimation of the rheological parameters $c$ and $n$. The variability of these parameters for events occurred in the same torrent has been evidenced in past investigations and is shown in Table 2 . The choice of the most reliable $[c, n]$ pair for the debris flow event that is being examined is therefore crucial. Since the dynamic behavior of a debris flow changes in time and also changes for different events any choice regarding the rheological parameters for debris flows hazard assessment purposes is inevitably affected by uncertainties. A method is proposed here to evaluate the effects of these uncertainties on the simulation results. 


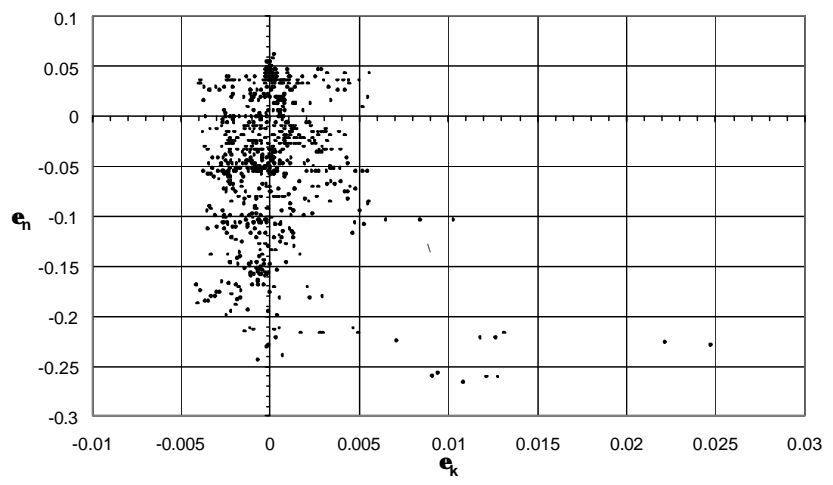

Fig. 7. Dispersion of $\varepsilon_{k}$ and $\varepsilon_{n}$ in time, in correspondence to the upstream cross section, for $n=0.75$. $\mathrm{d} n=.55$.

By simply differentiating Eq. (9) with respect to $n$ the following formula can be obtained for a constant discharge (see appendix for derivation):

$\varepsilon_{n}=\frac{\partial h}{h}=-\frac{1}{n+1} \ln h \cdot \partial n$

which shows that the relative error in the estimation of the flow depth is proportional to the uncertainty in the estimation of the parametern. This means that the relative error in the estimation of the flow depth depends on the uncertainties in determining the rheological behavior of the debris flow mixture. If no measurements were available for the studied case, a practitioner or a technician who had to chose a value for $n$ would probably assume $n$ equal to the mean value of the maximum $(n=1.3)$ and minimum $(n=0.2)$ values obtained in past simulations, that is $n=0.75$. In this case the $\partial n$ term would result equal to about 0.55 . The relative error $\varepsilon_{n}$ has been therefore computed assuming $\partial n=0.55$ and $n=0.75$. In Fig. $7 \varepsilon_{n}$ is compared with $\varepsilon_{k}$. Each plotted point refers to the same $h(t)$ recorded value at the downstream cross section. From this comparison it is shown that the order of magnitude of $\varepsilon_{n}$ falls in the range $[-0.27 ; 0.062 ;]$ and it is much greater than the range of variation of $\varepsilon_{k}$.

It would also be possible for a practitioner to decide to assume, for safety purposes, the $n$ value that leads to the highest $h$ value. In this case the uncertainty in the estimation of $h$, due to the assumption of the value of $n$ in the range [0.2;1.3] that causes the largest $h$, would be much higher than in the previous case and (13) could not be used to estimate it, since Eq. (13) is obtained with an infinitesimal approach. Alternatively, the first term in Eq. (13) can be calculated by means of a finite difference equation, so that $\varepsilon_{n}$ transforms into:

$\varepsilon_{n} \cong \frac{h_{n 1}-h_{n 2}}{\bar{h}}=\frac{\left(\frac{Q}{\alpha c \sqrt{S_{f}}}\right)^{\frac{1}{n_{1}+\beta}}-\left(\frac{Q}{\alpha c \sqrt{S_{f}}}\right)^{\frac{1}{n_{2}+\beta}}}{\bar{h}}$

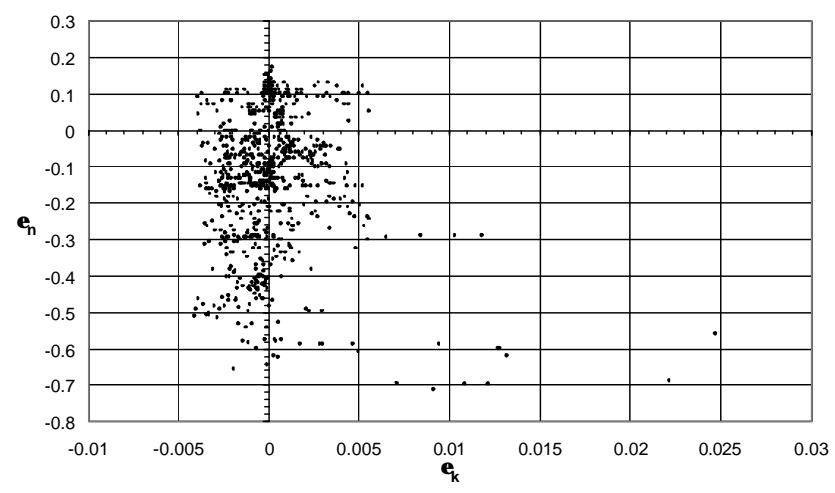

Fig. 8. Dispersion of $\varepsilon_{k}$ and $\varepsilon_{n}$ in time, in correspondence to the upstream cross section, for $n_{1}=1.3$ and $n_{2}=0.2$

where $n_{1}=1.3$ and $n_{2}=0.2$ and

$\bar{h}=\frac{\left(\frac{Q}{\alpha c \sqrt{S_{f}}}\right)^{\frac{1}{n_{1}+\beta}}+\left(\frac{Q}{\alpha c \sqrt{S_{f}}}\right)^{\frac{1}{n_{2}+\beta}}}{2}$

In Fig. 8 Eq. (14) has been plotted versus $\varepsilon_{k}$ for the debris flow discharges computed in the upstream cross section. In this case the relative error is of course higher than in Fig. 7.

All this shows that the uncertainties in the determination of the rheology have a greater influence on the simulation results than the approximations made neglecting the differential terms of the Saint Venant equation. This shows that for our examined event if the complete Saint Venant equation were employed no significant improvement in the results would have been obtained.

\section{Conclusions}

The rheological parameters of a debris flow that occurred in the Summer 2004 in an instrumented basin on the Italian Alps have been estimated by means of a mathematical model, imposing the best fit between simulated results and the recorded hydrograph. The analysis shows: (i) the rheological behaviour of this debris flow event is different from other debris flows previously occurred in the same torrent; (ii) the analysis of the relative influence of the different terms of the Saint Venant equation reveals the predominance of the resistance term over the remaining terms; (iii) the value of the error made neglecting these latter is much smaller than the error made simulating the complex and very irregular debris flow profile with a deterministic model; this suggests the use of a very simple and approximated mathematical model (the kinematic model) to simulate the debris flow propagation; (iv) since the resistance terms are closely related to the rheological behaviour of the mixture, it is more important to reliably estimate the rheological parameters used in the simulation than focusing on the choice of the most suitable mathematical and numerical schemes needed to solve 
the complete Saint Venant equation system. This latter consequence has been also evidenced by a comparison between the relative error due to uncertainties in determining the rheology and the relative errors due to the kinematic approximation. These conclusions are valid for a debris flow that occurred in a relatively simple torrent, with straight channel and without erosion and deposition.

\section{Appendix A}

\section{Derivation of Eq. (10)}

The momentum equation in uniform flow conditions holds:

$Q=A U=A c h^{n} \sqrt{S_{f}}$

For a rectangular cross section it is:

$A=b h$

while in general, it is (if $A$ is approximated by a monomial function):

$A=\alpha h^{\beta}$

where $\alpha$ and $\beta$ are parameters that depend on the shape of the cross section.

Using Eq. (A3) in Eq. (A1), one obtains:

$h=\left(\frac{Q}{\alpha c \sqrt{S_{f}}}\right)^{\frac{1}{n+\beta}}$

For a given discharge, Eq. (A4) can be used to calculate the debris flow depth, for given cross section geometry, roughness and bed slope.

Differentiating Eq. (A4) with respect to $S_{f}$, holds

$\frac{\partial h}{\partial S_{f}}=\left(\frac{1}{n+\beta}\right)\left(\frac{Q}{\alpha c \sqrt{S_{f}}}\right)^{\frac{1}{n+\beta}-1} \frac{Q}{\alpha c}\left(-\frac{1}{2}\right)\left(S_{f}\right)^{-3 / 2}$

Dividing Eq. (A5) by Eq. (A4), holds:

$\frac{\partial h}{h \partial S_{f}}=\left(\frac{1}{n+\beta}\right)\left(\frac{Q}{\alpha c \sqrt{S_{f}}}\right)^{-1} \frac{Q}{\alpha c}\left(-\frac{1}{2}\right)\left(S_{f}\right)^{-3 / 2}$

and therefore

$\frac{\partial h}{h}=-\frac{1}{2(n+\beta)} \frac{\partial S_{f}}{S_{f}}$

For a rectangular $(\beta=1)$ cross section, Eq. (10) holds.

\section{Appendix B}

\section{Derivation of Eq. (13)}

Differentiating Eq. (A4) with respect to $n$ holds:

$$
\begin{aligned}
\frac{d h}{d n} & =\left(\frac{Q}{\alpha c \sqrt{S_{f}}}\right)^{\frac{1}{n+\beta}}\left(-\frac{1}{(n+\beta)^{2}}\right) \ln \left(\frac{Q}{\alpha c \sqrt{S_{f}}}\right)= \\
& h\left(-\frac{1}{(n+\beta)^{2}}\right) \ln \left(h^{n+\beta}\right)
\end{aligned}
$$

From Eq. (B1) one obtains:

$\frac{\partial h}{h}=\left(-\frac{1}{n+\beta}\right) \ln (h) \cdot \partial n$

For a rectangular $(\beta=1)$ cross section, Eq. (13) holds: Notations:

$b$ :

A

$h:$

$n:$

$Q:$

$\alpha, \beta$ :

cross section width

cross section area

water sediment depth

rheological parameter

debris flow discharge

parameters depending on the shape

of the cross section

Acknowledgements. The authors wish to thank the reviewers for their suggestions to improve the quality of the paper, particularly S. P. Pudasaini for the useful discussion on the several aspects of debris flow modelling.

Edited by: G. Lollino

Reviewed by: S. P. Pudasaini and another referee

\section{References}

Abbott, M. B.: An introduction to the method of characteristics, American Elsevier, New York, 1966.

Abbott M. B.: Computational hydraulics: elements of the theory of free surface flows, Ashgate, Vermont, 1992.

Arattano, M. and Savage, W. Z.: Modelling debris flows as kinematic waves, Bulletin of the IAEG, 49, 95-105, 1994.

Arattano, M., Deganutti, A. M. and Marchi, L.: Debris flow monitoring activities in an instrumented watershed on the Italian alps, Proceedings of the First International ASCE Conference on Debris-Flow Hazard Mitigation: Mechanics, Prediction and Assessment, San Francisco, Ca, August 7-9, 506-515, 1997.

Arattano, M.: On debris flow front evolution along a torrent, Physics and Chemistry of the Earth Part B 25(9), Elsevier Science Ltd., 733-740, 2000.

Arattano, M. and Franzi L.: On the evaluation of debris flows dynamics by means of mathematical models, Nat. Hazards Earth Syst. Sci., 3, 539-544, 2003.

Arattano, M. and Franzi, L.: Analysis of different water-sediment flow processes in a mountain torrent, Nat. Hazards Earth Syst. Sci., 4, 783-791, 2004. 
Ayotte, D. and Hungr, O.: Calibration of runout prediction model for debris flows avalanches, Proceedings of the Second International Congress on Debris Flows Hazard Mitigation: mechanics, prediction and assessment, A.A. Balkema, Rotterdam, 505-514, 2000.

Coussot, P.: Steady, laminar, flow of concentrated mud suspensions in open channel, J. Hydr. Res. 32, 535-539, 1994.

Cunge, J. A., Holly Jr., F. M., and Verwey, A.: Practical aspect of computational River hydraulics, Pitman Publishing Limited, Boston, 1980.

Deganutti, A. M., Arattano, M., and Marchi, L.: Debris flows in the Moscardo Torrent. National Research Council of Italy, Institute for Hydrological Protection (IRPI) Internal Report (videocassette), 1998.

Egashira, S., Miyamoto, K., and Itoh, T.: Constitutive equations of debris flows and their applicability, First int. conference on debris flows hazard mitigation, 340-349, 1997.

Ghilardi, P. and Natale, L.: Debris flow propagation on urbanized alluvial fans, Proceedings of the Second International Congress on Debris Flows Hazard Mitigation: mechanics, prediction and assessment, A.A. Balkema, Rotterdam, 471-477, 2000.

Hashimoto, H., Park, K., and Hirano, M.: Numerical Simulation of small debris flows at Mt. Unzendake, Proceedings of the Second International Congress on Debris Flows Hazard Mitigation: mechanics, prediction and assessment, Balkema, Rotterdam, 177$183,2000$.

Hirano, M., Harada, T., Banuhabib, M. E., and Kawahara, K.: Estimation of hazard area due to debris flow. Proceedings of the First International ASCE Conference on Debris-Flow Hazard Mitigation: Mechanics, Prediction and Assessment, San Francisco, CA, August 7-9, 697-706, 1997.

Honda, N. and Egashira, S.: Prediction of debris flow characteristics in mountain torrents, Proceedings of the First International ASCE Conference on Debris-Flow Hazard Mitigation: Mechanics, Prediction and Assessment, San Francisco, CA, August 7-9, 707-716, 1997.

Hungr, O.: A model for the runout analysis of rapid flow slides, debris flows, and avalanches, Canadian Geotechnical Journal 32, 610-623, 1995.

Hutter, K., Svendsen, B., and Rickenmann, D.: Debris flow modeling: a review, Continuum Mech. Thermodyn, 1-35, 1996.

Iverson, R. M.: The physics of debris flows, Reviews of Geophysics, 35(1), 245-296, 1997.

Iverson R. M., Denliger R. P., LaHusen R. G., and Logan, M.: Two phase debris flow across 3-D Terrain: Model predictions and experimental tests, Second International conference on debris flows hazard mitigation, edited by: Wieczorek, G. F. and Naeser N. D., 521-529, 2000.

Jan, C. D. J.: A study on the numerical modelling of deris flows, Proceedings of the First International Congress on Debris Flows Hazard Mitigation: mechanics, prediction and assessment, San Francisco, CA, August 7-9, 717-725, 1997.
Jin, M. and Fread, D. L.: 1D Modelling of mud/debris unsteady flows, Journal of hydraulic engineering, 125, 8, 827-834, 1999.

Marchi, L., Arattano, M., and Deganutti, A. M.: Ten years of debris flows monitoring in the Moscardo Torrent (Italian Alps), Geomorphology, 46 (1/2), 1-17, 2002.

Nsom, B., Longo, S., Laigle, D., and Arattano, M.: Debris flow rheology and flow resistance, Thematic Report, U.E. contract Debris Flow Risk n ${ }^{\circ}$ ENV4-CT96-0253, Institute for Hydrological Protection (IRPI) Internal Report, 1-49, 1998.

Petrascheck, A. and Kienholz, H.: Hazard assessment and hazard mapping of mountain risks - example of Switzerland, in: DebrisFlow Hazards Mitigation: Mechanics, Prediction, and Assessment, edited by: Rickenmann, D. and Chen C. L., Proceedings 3rd International DFHM Conference, Davos, Switzerland, September 10-12, Rotterdam, Millpress, 25-38, 2003.

Pierson, T. C. and Costa, J. E.: A rheological classification of subaerial sediment water flow, Geol. Soc. of America, Rev. in Engineering and Geology, 7, 1-12, 1987.

Pudasaini, S. P. and Hutter, K.: Granular avalanche model in arbitrarily curved and twisted mountain terrain: a basis for the extension for debris flows, Proceedings of the Third International Congress on Debris Flows Hazard Mitigation: mechanics, prediction and assessment, Millpress, Rotterdam, 491-502, 2003.

Pudasaini, S. P. and Hutter, K.: Rapid Shear Flows of Dry Granular Masses Down Curved and twisted Channels, J. Fluid Mech., 495, 193-208, 2003.

Pudasaini, S. P., Wang, Y., and Hutter, K.: Modelling Debris Flows Down General Channels, Nat. Hazards Earth Syst. Sci., 5, 799819, 2005.

Regione Piemonte, 2002: Deliberazione 45-6656, Indirizzi per l'attuazione del PAI nel settore Urbanistico, Bollettino Ufficiale n. 30, 2002.

Rickenmann, D.: Empirical Relationship for debris flows, Natural Hazards, Kluver Academic Publisher, 47-77, 1999.

Suzuky, K., Watanabe, M., Kurihara, T., and Segawa, T.: Field study on debris and sediment flows in a small mountain torrent, Proceedings of the XXV IAHR Congress, Tokyo, 102-108, 1993.

Suwa, H. and Yamakoshi, T.: Estimation of debris flow motion by field survey. Proceedings of the Second International Congress on Debris Flows Hazard Mitigation: mechanics, prediction and assessment, Rotterdam, A.A. Balkema, 293-299, 2000.

Takahashi, T.: Mechanical characteristics of Debris Flow, J. Hydr. Division, ASCE, Vol. 104, No. HY8, 1153-1169, 1978.

Takahashi T.: Debris Flow on prismatic open channel, J. Hydr. Division, ASCE, Vol. 106, No. HY3, 381-396, 1980.

Takahashi, T.: Debris Flows: IAHR/AIRH monograph, A.A. Balkema, Rotterdam, 1991.

Takahashi, T. and Nakagawa, H.: Estimation of flood/debris flow caused by overtopping of a landslide dam, Proceedings of the XXV IAHR Congress, Tokyo, 117-124, 1993. 